\title{
Escrito sobre la piel. La memoria tatuada en la obra autobiográfica de Naomi Kawase
}

\author{
Writting Under the Skin. Tattooed Memory \\ in Naomi Kawase's Autobiographic Work
}

JOHANNA CAPLLIURE*

\begin{abstract}
Resumen: La autobiografía es escritura de la historia de las vidas y esta solo puede ser relatada con el cuerpo. Por eso, el lugar de la ficción, de la historia y de la memoria nos acerca a un conocimiento diverso. Tomaremos la historia de la directora japonesa Naomi Kawase como estudio sobre la escritura autobiográfica en el cuerpo. En el film Kya Ka Ra Ba A (2001) Kawase decide tatuarse el mismo dibujo que su padre. Ella nunca le conoció. Por esa razón, intenta construir una memoria afectiva a través de contarse su propia historia en el cine. La tinta del relato es la tinta del tatuaje.

Palabras clave: autobiografía, memoria, cuerpo, relato, Naomi Kawase, epistemologías diversas.
\end{abstract}

\begin{abstract}
The autobiography is the writting about the life's stories and they only can be narrated with the body. Therefore, the place of the fiction, History and memory approach us at a divergent knowledge. We take the story from the Japanesse filmmaker Naomi Kawase to study about the autobiographic writting in the body. In the film Kya Ka Ra Ba A (2001), Naomi Kawase decides tattooing the same drawing that her father. She never met him. For this reason, she tries build a afective memory through that she tells her own story in the cinema. The story's ink is tattoo's ink. Keywords: autobiography, memory, body, story, Naomi Kawase, divergent epistemologies.
\end{abstract}

«Je n'ai jamais parlé d'autre chose que de moi », Allain Robbe-Grillet

¿Cómo podría conocer el mundo a través de un cuerpo fracturado, traumatizado y carente de amor? Todo cuerpo se inscribe en el mundo a través de un yo que se suma a su historia. La forma de inscripción es la del lenguaje y la manera de escritura se conduce entre la narra-

Fecha de recepción: 10/06/2016. Fecha de aceptación: 27/07/2016.

* Universitat de Valéncia-UVEG, Doctoranda en el programa Pensamiento Filosófico Contemporáneo. Líneas de investigación: Entendiendo el pensamiento como praxis, como "practique sauvage", sus investigaciones atraviesan la hermenéutica crítica, los estudios de género y los estudios culturales (pensamiento postcolonial), la filosofía de la historia y las investigaciones entre comunidad, activismo y resistencia, relato y ficción "versus" historia. Actualmente está investigando las relaciones entre autobiografía, autoficción y autorreflexión. Últimas publicaciones bajo la misma temática: "Le désir d'Orient. Disonancias de una nómada en época colonial. Los textos de Isabelle Eberhardt” en París Albert, S. e Comins Mingol, I. (Eds.), La interculturalidad en diálogo: estudios filosóficos, Editorial Thémata, 2016. "De polizones, marineros sin capitán y extranjeros nómadas. La autobiografía como travestismo en Isabelle Eberhardt" en Documentos para la resistencia. Pedagogías postfeministas para la igualdad. Número 7 de la Col.lecció "Creativitat i recerca" editada por el Institut Universitari de Creativitat i Innovacions Educatives y el Centre Documentació Art Valencià Contemporani "Romà de la Calle” (CDAVC), UVEG, 2015. 
ción y la vida. Inscribir un cuerpo en la historia es escribir el cuerpo entre las estructuras de percepción y las estructuras del self; entre el mundo sensible y el mundo espiritual; entre la memoria y la creación de un relato. La conciencia de un cuerpo existente ocupa un lugar en el mundo y se hace mundo. Sin embargo, la dificultad de concebir el mundo a través de este cuerpo y hacerse cuerpo mediante este yo, descubre la latencia de un cuerpo anómalo. La partición ontológica entre un cuerpo y el cuerpo anómalo se evidencia en su estar en el mundo, en su escritura como yo, en su autobiografía decolonial. Siempre atendiendo la decolonialidad en cuanto travesía entre un borde y otro, como frontera misma de las diferentes exigencias de conceptualización. Es decir, utilizo la definición que se ha otorgado desde el pensamiento crítico para diferenciar la descolonización del siglo XIX de la decolonización del XX en la que el ejercicio ya no es solo político, geográfico o jurídico, sino epistemológico, lingüístico, de raza y de clase. Y, por supuesto, en tanto que identificación de las definiciones de cuerpo sujeto a nociones movedizas frente al reduccionismo epistemológico.

Por lo tanto, el posicionamiento que planteo en este texto se vincula a la importancia del cuerpo como lugar de construcción de la autobiografía a partir de su introducción en el relato de la historia mediante la escritura. Puesto que, por un lado, "(l)e texte opère dans une vie, non dans le vide", tal y como nos dice Serge Doubrowsky -el crítico de la autoficción. Mientras que, por otro lado, siguiendo algunos estudios fenomenológicos- Merlau Ponty en la base, llegamos a entender nuestra relación con el mundo a través de la situación de nuestros cuerpos en el plano físico e histórico en el espacio. El cuerpo accede a su propia historia mediante el contacto directo con el mundo. Pero además, a través de nuestros cuerpos somos contemplados en el mundo. La experiencia del yo y la historia es circunscrita en el nombre del cuerpo.

Otro acercamiento relevante en nuestra apuesta es, en este caso, las investigaciones de la performatividad (incluyendo en sus orígenes a J.L. Austin -How to Do Things With Words, 1962- y posteriormente, en la teoría queer, a Judith Butler -Gender Trouble, 1990), que nos hacen abocarnos a la suma del cuerpo y la palabra en la configuración existencial del sujeto yo.

Y finalmente, son las críticas literarias las que nos ayudan a plantearnos cómo la autobiografía adquiere un lugar incuestionable para entender la vida del yo en su propio relato. La escritura es la acción performativa del cuerpo en la historia. Es decir, al contarse uno se está haciendo. "Yo me cuento mi historia a mí mismo. Me relato mi vida, la recito y la cuento para mí", decía Friedrich Nietzsche en su autobiografía: Ecce Homo. Ciertamente son muchos los autores que se implican en la acción escrituario-performativa de la autobiografía, puesto que la autos-bios-grafé tiene inscrito en su nominación la escritura. Sin ambages, diríamos que la autobiografía es la escritura de la vida del yo. No obstante, la autobiografía ya no es solo aquella que se opera con el negro sobre blanco; existen diferentes formas de escritura. De hecho, las nuevas maneras de registro audiovisual: cámaras fotográficas, cámaras de vídeo y grabadoras de audio se incluyen como tecnologías de una nueva narración del yo que hace inclusive la técnica como mecanismo ${ }^{2}$. Pero también, su expresión se nos

1 Serge Doubrovsky, Autobiographiques. De Corneille à Sartre, Paris, PUF, 1998, p. 70.

2 La importancia de los estudios de Philippe Lejeune, como crítico de la autobiografía, nos aproximan a las diferentes formas de dicho género llevándonos a ciertas paradojas al transitar por los nuevos medios autobiográficos. 
ofrece como nuevos modos de narratividad y nuevos marcos epistemológicos. La creación audiovisual es el espacio de encuentro que nos interesa apreciar en esta lectura. En primer lugar según la deriva del célebre crítico de la autobiografía: Philippe Lejeune y posteriormente con pensadores sobre el relato íntimo del yo como Nora Catelli.

Reconozco que es de suma relevancia trasmitir cómo la elección de géneros que operan en las lindes entre la historia y la autobiografía à la manière de Lejeune, a saber: la ficción, la antropología, la novela, la vuelta del autor producen un nuevo campo para las epistemologías diversas. La escritura del yo, las estructuras del self, se prodigan dentro de las «micronarrativas» como una nueva posibilidad acerca de la historia, como un nuevo fenómeno historiográfico. Pero, con la excepción que conlleva su subjetividad y su fuerza poética. El propio Philippe Lejeune cae en la contradicción de la autobiografía. Si bien en una primera etapa, en su más que reconocido estudio sobre el pacto autobiográfico, pone énfasis en el contrato de veracidad entre el escritor, la narración del yo escritor y el lector, haciendo de la autobiografía y los estudios biográficos un señalado recurso historiográfico de la Modernidad; más tarde renuncia a esta única vía en virtud de los relatos de los otros y a favor de otros modos de escritura del relato del yo. Así abre su campo de análisis a una autobiografía de fuerza poética que se aproximaría al pacto ambiguo que declara Manuel Alberca en relación a la estrecha ambivalencia entre el relato autobiográfico y la autoficción. Sin duda alguna, esta fractura se evidencia en aquellas palabras de Roland Barthes par Roland Barthes en las que el pensador francés esgrime la insuficiencia de la escritura narrativa para hacer el yo: «El Texto no puede contar nada; se lleva mi cuerpo a otra parte, lejos de mi persona imaginada, hacia una suerte de lengua sin memoria».3

$\mathrm{Y}$ entonces, nos preguntamos: ¿qué sucedería cuando intentamos escribir el relato del yo a partir de un cuerpo sin memoria, sin arraigo y traumatizado por su propia historia? ¿Es posible el relato de un cuerpo anómalo? ¿Cómo entenderíamos el relato del yo de un cuerpo sin memoria? ¿Como autobiografía o autoficción? ¿Debemos seguir manteniendo estas limitaciones estructurales en un discurso del cuerpo anormal? Desde luego, estos interrogantes no auguran más que una imagen del yo difusa o borrada. Aunque no debemos restar valor a los epítomes que se trasforman en pieza clave de lo que para nosotros es la autoficción como salvación. Para ello, en nuestra tentativa de dar explicación a estas cuestiones hemos escogido el trabajo audiovisual de la cineasta Naomi Kawase.

En la obra de la directora japonesa el espacio aparece anegado del amor perenne. ¿Por qué te quiero? Y, no estás. Todo plano de Naomi Kawase rezuma amor, pero un amor que duele. Ahogarse en tantas lágrimas de dolor, de tristeza y de un constante decirse: "quizá no tuviera que estar aquí". Quizá Kawase no tuviese que existir. Y sin embargo, Naomi Kawase existe y filma películas que la hacen vivir dentro y fuera del celuloide, en dos yos- como diría Nora Catelli, en contacto con los espectadores, en las salas de cine, detrás de una cámara o delante de ella dejando ver un mechón de su cabello, una fotografía tomada hace algún tiempo, mostrándose en cuerpo entero... A estos epítomes son a los que me refiero. En los que el cuerpo se epitomiza como intento narrativo-performativo del yo. También existe su voz: a veces, suave y dulce. A mí, me gusta cuando tararea. No tiene una bonita voz, pero me fascina lo delicada que consigue parecer y cómo hace que en ese momento todo se disperse

3 Barthes, Roland Barthes par Roland Barthes, Paris, Seuil, 2004, p. 18. 
cayendo en la ternura de su tono. Otras veces, su voz es firme y rotunda. Cuando interpela a sus interlocutores y no halla respuesta o se siente confusa ante la información que recibe emplea ese tono que en la lengua japonesa siempre me ha recordado a los cuchillos con los que se elaboran los platos nipones y que son capaces de cortar una cebolla, laminar un salmón o trocear una carne: siempre con un movimiento seco y directo.

La realizadora japonesa Naomi Kawase fue abandonada por sus padres siendo un bebé. Adoptada por sus tíos-abuelos, su vida y obra transcurre entre el constante cuestionamiento sobre su identidad y sus orígenes, y la búsqueda incesante de sus padres. Esa pregunta constante por el porqué fue abandonada, por qué sus padres biológicos no quisieron hacerse cargo de ella, por qué les costó tanto querer conocerla, parece el motor vital y creativo de Naomi Kawase. Por eso, podemos afirmar que su cine es un cine autobiográfico. Vida encarnada en obra y obra escrita sobre la piel. La historia de Naomi se escribe sobre la piel de su protagonista, la propia Kawase. Si su trabajo se entiende como autobiográfico no es especialmente por contar su vida, sino por hacer su vida mientras opera con la cámara. Parece que con cada fotograma se construye el vacío que la memoria no pudo capturar porque nunca existió y ahora no reconstruye sino que construye por primera vez y en primera persona la vida de Kawase. ¿Debemos seguir hablando de autobiografía, de performance autobiográfica o de autoficción audiovisual? Siguiendo a Doubrowsky, quien definió por primera vez la autoficción, podemos exponer en sus mismas palabras que: "[s]i la verdad de un sujeto es la ficción que rigurosamente se construye, la verdad de una ficción es ficticia. O mejor, lo ficticio, para un sujeto es el orden mismo de lo real. La ficción no es fantasía" ${ }^{4}$.

Por todo esto, para Kawase es tan importante la memoria encarnada puesto que es en su propio cuerpo donde puede llegar a encontrar las respuestas sobre quién es y quién fueron sus progenitores. Y, por eso mismo, es crucial que mediante su cámara pueda traer la ficción de lo real de su vida pasada. Para ello, las fotos del álbum de familia podrían ayudar, pero sin embargo es en los senos seniles de su tía-abuela convertida en madre, aquellos que nunca le dieron de mamar, donde se cobija sin hallar consuelo. Sus manos se alargan como la lente de la cámara para poder acercar un pedazo de lo que podría ser ella misma. De hecho, se dice de su cine que es táctil. Kawase hace compadecer a los objetos ante la cámara, como en el caso de Caracol: algunas piezas de fruta, platos de comida, flores, objetos de la casa, incluso el rostro de su tía abuela que intenta tocar, palpar, acariciar, con curiosidad, pero también con cierta precaución alargando sus deditos midiendo la distancia/la cercanía entre los objetos y su cuerpo; como las antenas de un caracol. “¿Por qué los árboles se balancean con el viento? Para poder tocarse"- se dice la propia autora en En sus brazos (1992).

Por supuesto, su trabajo se vincula con el cine de los afectos: nos hace palpitar el corazón y que la cámara tiemble. La cámara y el público acompaña un momento de miedo, preocupación, emoción o el sollozo de Naomi Kawase. Lo que se dirige en otras palabras hacia un "cine en lágrimas" ${ }^{5}$ un cine lacrimógeno. "El cine en lágrimas- dice Gonzalo de Lucas- es borroso y nítido a la vez. Su efecto es la expresión de un sentimiento o la formación de una emoción que aflora y conmueve un cuerpo y nubla la percepción del mundo"6. Un cine

\footnotetext{
4 Doubrowsky, Serge, Autobiographiques. De Corneille à Sartre, Paris, PUF, 1998, p. 78.

5 De Lucas, Gonzalo, "El cine tiembla" en López, J.M.(ed), El cine en el umbral, Madrid, T\&B Editores, 2008.

6 Íbid. p. 40.
} 
lacrimógeno, no en cuanto al llanto de Kawase o a los efectos de empatía o emoción que podamos tener sobre su cine, sino por la sensibilidad de la película. El ojo se llena de la solución salina antes de colocarse encima de la retina emborronando toda imagen, se detiene recogiendo toda la masa acuosa sobre el lagrimal y pronto desciende recorriendo la mejilla. Enfoque y desenfoque.

Por otra parte, si la autobiografía es escritura de la historia de las vidas esta solo puede ser relatada, escrita en el cuerpo viviente y doliente de la autora. Y que, sin embargo, es capaz de amar y de escribir su historia en su propio cuerpo filmando su propia vida y dando vida. El hecho de dar a luz a su hijo Mitzuki no cesa de recordarme el nacimiento de este y cómo lo filma la directora todavía unida a él por el cordón umbilical en Tarachine (Maternidad) (2006). La cámara se convierte en parte de su cuerpo como el cordón umbilical entre su cuerpo y la vida que le ha tocado vivir. Pero, también es cierto que la cámara tiene una función de escritura autoficticia (autofictionnelle) y que en ella se recrea. Dice Paul de Man: "puede contener numerosos sueños y fantasmas, (...) estas desviaciones de la realidad están enclavadas en un sujeto cuya identidad viene definida por la incontestable legitimidad de su nombre propio"'. Por eso, Kawase intenta reconocerse en el nombre del padre y tatúa su cuerpo tras conocer la muerte de su padre. El tatuaje es el mismo que llevaba este desconocido que es su padre y con el que reescribe su historia. Puesto que el texto en tanto que texto y el cuerpo en tanto que cuerpo vivo no cesa de imponerse como reescritura de vida. Observemos el film que relata este encuentro con el pasado relatado en el tatuaje del padre. Kya Ka Ra Ba A (El cielo, el viento, el fuego, el agua de 2001) saca a la luz cómo la memoria de Naomi Kawase se construye en torno a su propio cuerpo herido. La yoidad, esa presencia y existencia del yo bajo el cuerpo en el mundo es dibujada mediante la tinta del relato. El espacio en el que se mueve es difuso, la bruma y la desaparición de los objetos producen una inestabilidad en la atmósfera de lo films de Kawase como la tinta en contacto con el agua. Pero cuando esta se fija sobre la piel, el cuerpo se ve sujeto a su historia: Historia e historia personal.

El tatuaje no es una vestimenta o una forma de cubrir el cuerpo. En esta ocasión el cuerpo escrito, el cuerpo pintado con permanencia es la forma de escritura de la memoria. Una memoria que tampoco existe, pero que siendo el cuerpo aguijoneado de tinta se escribe sobre la piel. Como un aguijón de dolor, de amor, se configura como una tentativa de comprensión sobre lo acaecido. Aunque también, la aguja clavada sobre la piel introduce el pigmento, la tinta con la que escribir la historia de una vida, la historia de un cuerpo que es el del padre y que ahora también es el de la hija. Las formas narrativas plásticas del tatuaje como las audiovisuales se observan parejas a la fuerza poética. Por lo tanto, la evocación de la imaginación como estructura de conocimiento bajo la forma poética se hace evidente en el nuevo relato posmoderno y en el relato de la autora. Las imágenes subyugadas al trauma y a la herida del cuerpo, al tachón de la escritura del relato de la vida se erige como una memoria fantasmática del cuerpo.

Por consiguiente, traer a la luz una memoria que no existe y que es construida mediante el trabajo de investigación y de construcción del yo por la artista es la labor autoficcional que se ha impuesto como vida y relato de sí misma. El tatuaje es parte de un fantasma traído

7 Man, Paul de, "La autobiografía como des-figuración” en La retórica del romanticismo, Madrid, Akal, 2007. 
a la actualidad del cuerpo de Kawase, es la forma de evocar algo existente del pasado. El padre se presenta/se representa en el dibujo de la tinta sobre la piel. Y el cuerpo vivido celebra que está todavía por venir.

\section{Bibliografía}

Barthes, Roland (2004): Roland Barthes par Roland Barthes, Seuil, Paris.

Catelli, Nora (2006): En la era de la intimidad. Seguido de "El espacio autobiográfico", Beatriz Viterbo Editora, Rosario.

Doubrovsky, Serge (1998): Autobiographiques. De Corneille à Sartre, PUF, Paris.

Lejeune, Philippe (1994): El pacto autobiográfico y otros estudios, Megazul-Endymion, Madrid.

López, José Manuel (ed) (2008): El cine en el umbral, T\&B Editores, Madrid.

Man, Paul De (2007): "La autobiografía como des-figuración” en La retórica del romanticismo, Akal, Madrid.

Nietzsche, Friedrich (2011): Ecce Homo, Alianza Editorial, Madrid. 